\title{
Desenvolvimento do professor iniciante de língua estrangeira: contribuições da Instrução ao Sósia
}

\section{Development of beginner foreign language teacher: contributions of Instruction to the Double}

Francieli Freudenberger Martiny' (UFPB)

\begin{abstract}
Resumo: O presente texto busca demonstrar quais dimensões do trabalho docente a Instrução ao Sósia permite acessar, além de discutir em que medida tais dimensões podem indicar desenvolvimento de uma professora iniciante de Língua Espanhola. A noção de desenvolvimento assumida nesta pesquisa advém de uma perspectiva vygotskiana tal como (re)interpretada pelo Interacionismo Sociodiscursivo. Também são referenciadas as contribuições da Clínica da Atividade com relação ao procedimento e às dimensões do trabalho humano. Os dados foram gerados a partir da condução de sessões mensais de Instrução ao Sósia com uma professora iniciante de Língua Espanhola em seu primeiro ano de atuação. A análise dos dados perfaz um caminho interpretativo a respeito da integração de uma ferramenta docente na atividade dessa professora, evidenciando indícios na produção linguageira que indicam processos desenvolvimentais.

Palavras-chave: Instrução ao Sósia; Professores Iniciantes; Língua Estrangeira; Desenvolvimento.
\end{abstract}

\begin{abstract}
This text aims at demonstrating what dimensions of teacher work are accessible through Instruction to the Double, as well as discussing the extent to which such dimensions may indicate development of a beginner Spanish teacher. The notion of development assumed in this research comes from a Vygotskian perspective as (re)interpreted by Sociodiscursive Interactionism. The contributions of Clinic of Activity, related to the procedure and to the human work dimensions, are also referred to. Data were generated by conducting monthly sessions of Instruction to the Double with a beginner Spanish teacher in her first year of work. Data analysis privileges an interpretative path regarding the integration of a teaching tool in this teacher's activity, highlighting evidences of developmental process in the language production.
\end{abstract}


Keywords: Instruction to the double; Beginner Teachers; Foreign Language; Development.

\section{Introdução}

Pensar a formação docente constitui-se um projeto desafiador, pois nesse processo estão interligados inúmeros fatores. Dentre eles, podem ser reconhecidas, dentre outras incontáveis, questões contextuais e sociais - que indicam o papel da educação e da escola em um determinado grupo cultural; questões acadêmicas e científicas - que apontam para tecnologias e perspectivas de ensino e aprendizagem; questões pessoais e afetivas - tanto dos formadores quanto dos professores em formação. Qualquer dispositivo ou processo de formação de professores, seja inicial ou continuada, deve buscar acolher e integrar essas complexas e numerosas dimensões, ainda que elas dificilmente possam ser integralmente reconhecidas e listadas.

Fica evidente, portanto, que perspectivas teóricas e metodológicas, elaboradas em distintos campos do saber, podem apenas contribuir com um determinado ponto de vista a respeito dos processos formativos. A visão do todo, se é que seja possível, advém da interlocução estabelecida a partir de áreas distintas.

O presente trabalho busca contribuir com um desses pontos de vista possíveis sobre a formação inicial do professor de Língua Estrangeira. Tal contribuição está fundamentada na concepção de que o desenvolvimento humano, assim como compreendido a partir do trabalho de Vygotsky (1985[1934]; 2009[1934]) não cessa na infância, mas permanece possível na fase adulta (BULEA, 2010). O ponto de partida para essa reflexão é a suposição de que os processos nos quais os professores iniciantes se envolvem trazem em si potenciais de contradição e conflito (SCHNEUWLY, 1994; 2009), o que pode dar origem a movimentos de ruptura e ressignificação de suas representações (BRONCKART, 2013). Esses processos são, desse modo, potencialmente desenvolvimentais.

A reflexão aqui proposta é elaborada a partir do quadro epistemológico do Interacionismo Sociodiscursivo aliado às proposições da Clínica da Atividade, tal como elaborada por Clot (2001a; 2001b). Tal relação não é nova no campo de formação de professores (MACHADO, 2004) e faz sentido à medida que ambos promovem a investigação do trabalho humano a partir de perspectivas que se complementam. 
No bojo dessas concepções, o objetivo do presente texto é reconhecer quais dimensões do trabalho docente a Instrução ao Sósia ${ }^{1}$ permite acessar. Além disso, busca-se discutir em que medida tais dimensões podem indicar desenvolvimento de uma professora iniciante de Língua Espanhola.

A fim de que seja possível tematizar o potencial de desenvolvimento docente acessivel a partir da Instrução ao Sósia (doravante laS) em contexto de formação docente inicial, será discutida, primeiramente, a noção de desenvolvimento que fundamenta o presente trabalho. Em seguida, será apresentado o dispositivo de laS, com enfoque na adaptação proposta pela Clínica da Atividade e sua relação com as dimensões do trabalho docente. Tais formulações serão retomadas na análise de alguns trechos de interação gerada com uma professora iniciante de Língua Espanhola que participou de sessões mensais de laS durante seu primeiro ano de docência. Esses dados foram gerados durante a realização da pesquisa de doutoramento (FREUDENBERGER, 2015a) e são aqui parcialmente apresentados e reinterpretados.

\section{Perspectivas sobre o desenvolvimento do professor iniciante}

Assumir uma perspectiva sócio-histórica a respeito do desenvolvimento humano implica, dentre outros aprofundamentos, reconhecer as fases da teoria elaborada por Vygotsky (2009[1934], dentre outros) e a maneira como a construção de seu posicionamento teórico impacta, ainda hoje, não apenas a compreensão do desenvolvimento infantil - foco central das investigações do pesquisador - como também a continuidade desse processo na fase adulta. Schneuwly (2009) sintetiza esse percurso, defendendo que nele há duas fases distintas: a primeira, quando Vygotsky define o ato instrumental como unidade de análise de suas investigações e a segunda, na qual o pesquisador identifica o significado da palavra, compreendido como uma generalização característica do pensamento verbalizado, como sua unidade de análise.

A adoção do significado das palavras como unidade de análise das pesquisas sobre o desenvolvimento humano ganha relevância, segundo Bota (2009), à medida que estabelece que a mediação promovida pela linguagem, e sintetizada para investigação no significado

\footnotetext{
${ }^{1} \mathrm{O}$ dispositivo de Instrução ao Sósia será apresentado na seção seguinte deste texto.
} 
das palavras, permeia todas as demais atividades ${ }^{2}$ humanas, incluindo aquelas envolvendo ferramentas e instrumentos - características do ato instrumental. Dessa maneira, a compreensão vygotskiana sobre o desenvolvimento humano privilegia uma visão sistêmica e semiótica sobre as funções e dimensões humanas, estudadas a partir das relações que elas estabelecem entre si. Desse modo, Vygotsky (1985[1934]) defende que o desenvolvimento (infantil) torna-se possível a partir do amadurecimento de funções cognitivas, desencadeado pela aprendizagem. Conforme o autor, é a aprendizagem que "ativa o desenvolvimento mental da criança, ao despertar os processos evolutivos que não poderiam ser atualizados sem ela" (VYGOTSKY, 1985[1934], p.112).

Percebe-se, assim, um movimento de autopropulsão, em termos de origens biológicas ou naturais, direcionado por processos de aprendizagem em contextos sócioinstitucionais. A esse respeito, Schneuwly (1994) argumenta que, para Vygotsky, há uma luta de opostos que promove o desenvolvimento: as formas primitivas do indivíduo entram em choque com as formas culturais com as quais ele se depara. O desenvolvimento pode, então, ser compreendido, conforme Schneuwly (2008), como um processo dialético de revolução e reorganização das funções psicológicas. Tal processo, nomeado de sociogênese por Miller (2011), dá origem às funções psicológicas superiores e, enquanto tal, opera a cada estágio de desenvolvimento, inclusive na fase adulta.

No âmbito do ISD, Bronckart $(2008$; 2013) argumenta que é o trabalho linguageiro de apropriação e interiorização do debate social que permite que novas generalizações - em termos vygotskianos - possam ser originadas, caracterizando, assim, o desenvolvimento humano. Desse modo, tendo por base a teoria do signo saussureana (SAUSSURE, 2004[1916]; 2006), Bronckart (2013) argumenta que a ruptura promovida pela internalização do signo linguístico permite que fatores internos e externos ao indivíduo, ambos essencialmente sociais, entrem em conflito, sejam negociados - com a mediação da linguagem - e possibilitem uma nova significação.

A partir desses postulados, o desenvolvimento humano pode ser compreendido como "um trabalho de ressignificação das representações de uma pessoa, possibilitado pela formulação de uma resolução pessoal ao conflito e ao debate social sobre a atividade"

\footnotetext{
${ }^{2} \mathrm{O}$ conceito de atividade humana, no presente trabalho, acompanha aquele proposto por Bronckart (2005), definida como o formato social que organiza e regula as interações do indivíduo com o meio, fazendo parte dos pré-construídos histórico-sociais. Já ação assume um estatuto interpretativo, uma vez que deriva de uma leitura da atividade ou mesmo do agir referente (BRONCKART; BULEA, 2006).
} 
(FREUDENBERGER, 2015b, p.63). É a mudança no trabalho interpretativo, promovida pelos conflitos vivenciados pelo indivíduo na sua interação com os pré-construídos sóciohistóricos, que caracteriza o desenvolvimento humano. Nesse sentido, Bulea (2010) defende que esse movimento permanece durante a fase adulta, uma vez que a atividade linguageira, realizada em uma diversidade incontável de gêneros textuais, disponibiliza aos indivíduos quadros sociais "no seio dos quais as pessoas são susceptíveis de reformular o incessante debate social, de interiorizá-lo, de geri-lo psicologicamente, e, por sua vez, de alimentá-lo" (p.168).

A perspectiva vygotskiana sobre o desenvolvimento humano também foi fundamental para a configuração conferida por Clot (2001a; 2001b) à laS. Esse procedimento foi criado por Ivar Oddone e sua equipe, na década de 1970, no quadro da Psicologia do Trabalho. O direcionamento dado aos trabalhadores era o seguinte: "Suponha que eu seja seu sósia e que amanhã eu deva lhe substituir no seu trabalho, quais são as instruções que você gostaria de me transmitir a fim de que ninguém perceba a substituição?" (ODDONE, RE, BRIANTE, 1981). O procedimento tinha originalmente como propósito investigar a experiência vivida pelos trabalhadores a fim de melhorar suas próprias condições de trabalho, assim como as prescrições a eles oferecidas.

Clot (2001a) assume que a atividade gerada pela laS ultrapassa a experiência imediata, tal como vivenciada pelos trabalhadores, e permite a duplicação do vivido em nova experiência, o que possibilita uma tomada de consciência do trabalhador, compreendida não como "a descoberta de um objeto mental inacessível anteriormente, mas a redescoberta - a recriação - desse objeto psíquico em um novo contexto que o 'faz ver de outra forma'" (CLOT, 2001a, p.272). A partir dessa constatação, o autor passa a promover pequenas adaptações no procedimento (CLOT, 2001b), a fim de potencializar um duplo movimento de deslocamento: o instrutor/trabalhador deve construir suas instruções em direção ao futuro e à outra pessoa - o sósia/pesquisador. Assim, acontece uma descrição de um agir singular e futuro, tendo por base uma generalização de experiências passadas, tomadas como representativas de uma maneira de fazer.

Ao ser assim objetivado, o realizado se descola da atividade e fica disponível para ser (re)utilizado em outros contextos futuros. É nessa característica que se encontra o potencial de desenvolvimento da laS: ao mediar a descoberta de novas possibilidades de ação (ao dar 
acesso ao real da atividade), ele transforma essa atividade real em recurso para uma nova realização. Cabe aqui destacar que o autor define o real da atividade não apenas como aquilo que se faz (reconhecido como atividade realizada), mas também aquilo que se tenta fazer, que se é impedido de fazer ou que não se tem condições de realizar (CLOT, 2007[1999]). Assim, tanto o possível quanto o impossível, o realizado e o impedido fazem parte do real da atividade.

O acesso a essa dimensão do trabalho é proporcionado pela presença do sósia, uma vez que ele promove, em termos vygotskianos, o contato social e artificial consigo mesmo, oferecendo uma resistência à atividade prescrita pelo trabalhador. Ou seja, o sósia tira a realização da atividade do campo da naturalidade e da recursividade e coloca obstáculos à sua realização. Isso porque ele, por um lado, não conhece o contexto no qual estará supostamente trabalhando e, por outro, deve se comportar da mesma maneira que o instrutor. Saujat $(2002$; 2005) argumenta que a laS possibilita dois momentos de confrontação, que levam o trabalhador a ver sua experiência com os olhos do sósia. 0 primeiro momento representa a confrontação do trabalhador a si mesmo, e ocorre durante a conversa face a face. Já o segundo remete à confrontação com a conversa em si e a escrita do comentário direcionado ao coletivo de trabalho.

Quando considerado o emprego da laS em contexto de formação inicial, há uma compreensão de que o procedimento sofre adaptações tendo em vista as especificidades do trabalho iniciante. Goudeaux e Stroumza (2004), por exemplo, apontam que os profissionais iniciantes podem ter dificuldade em acessar o real da atividade, ao privilegiar sua dimensão normativa a fim de cumprir com as supostas expectativas do sósia em relação ao seu trabalho. Essa tendência pode impedir os profissionais iniciantes de reconhecer novas possibilidades de ação, uma vez que eles procuram se aproximar de uma descrição da atividade conforme prevista na prescrição.

A pesquisa conduzida por Friedrich, Goudeaux e Stroumza (2005), em contexto de formação inicial de professores, complementa e exemplifica tais ponderações. Segundo as autoras, na argumentação de Clot (2001b), a experiência vivida é relegada a segundo plano, uma vez que é a percepção dos possíveis presentes no real da atividade que propulsiona o desenvolvimento. Já para as autoras, o vivido atua como suporte pontual da instrução, 
tanto no sentido ilustrativo de experiências já vividas, quanto no sentido de justificar decisões e comportamentos prescritos durante o procedimento.

Assim, o vivido pode apresentar três tipos de relação com os saberes, conforme representados durante a laS. Primeiramente, a experiência vivida pode fazer parte de um esquema de ação que foi revisto e corrigido, perfazendo um saber estável e possivelmente generalizável. Uma segunda relação diz respeito ao que Friedrich, Goudeaux e Stroumza (2005) chamaram de "saber da experiência", que remete ao seu pertencimento a uma situação específica. Ao ser utilizado, esse saber sempre passa pela mediação de si próprio, ficando preservado o papel da imprevisibilidade e da incerteza do agir. Por fim, a situação pode apresentar-se como "vivido puro", representado como singular e específico. Nesse caso, não existe experiência, mas fatos que, muitas vezes, são avaliados como erros ou falhas na competência do profissional em formação. O papel desempenhado por cada um desses tipos de experiência durante a laS é distinto. Assim, as autoras concluem que existe uma relação de dependência entre a capacidade de prescrever o trabalho ao sósia (e, portanto, exprimir os saberes da experiência) e a capacidade de distanciar-se do vivido.

Ainda que a discussão aqui proposta seja breve, é possível identificar aspectos característicos do desenvolvimento humano a partir de uma perspectiva sóciointeracionista. Tais aspectos envolvem um trabalho de reestruturação de significações promovido por conflitos com os quais a pessoa (ou trabalhador, nesse caso) se depara. A análise proposta neste texto busca evidenciar esse processo em uma professora iniciante a partir da condução de uma investigação exposta a seguir.

\section{A pesquisa sobre o trabalho de uma professora iniciante}

Para alcançar o objetivo de investigar a relação entre a laS e aspectos de desenvolvimento em professores iniciantes, são apresentados e analisados, no presente texto, trechos dos dados gerados durante a pesquisa de doutorado da autora (FREUDENBERGER, 2015a). Na oportunidade, três professores iniciantes foram acompanhados, com sessões mensais de laS, durante seus dois primeiros semestres letivos como professores responsáveis por turmas de Línguas Estrangeiras. 
O recorte aqui proposto foi gerado com a participação de apenas um desses participantes, uma professora iniciante de Língua Espanhola identificada com o nome fictício Taylor. Durante a geração dos dados, Taylor era aluna do curso de Licenciatura em Letras - Língua Espanhola de uma universidade federal, estando em seu terceiro ano de curso. A geração dos dados foi iniciada na metade de seu primeiro semestre como professora de dois grupos de Espanhol - Nível 1 e continuou durante todo o semestre seguinte, quando ela ministrou o Nível 2 para esses mesmos grupos de alunos. A pesquisadora e a professora, durante esse período, reuniam-se mensalmente para a realização da interação face a face proposta pela laS. Em seguida, a pesquisadora transcrevia a interação e encaminhava-a, juntamente ao áudio da interação, para que a professora produzisse um comentário escrito a partir de suas reações e análises do texto gerado conjuntamente.

O contexto de atuação de Taylor eram os cursos de Línguas Estrangeiras oferecidos pelo Departamento de Letras Estrangeiras Modernas da universidade à comunidade acadêmica e externa. Taylor atuava, portanto, como bolsista nesse contexto, sob supervisão de uma tutora, professora titular do referido departamento, que acompanhava e orientava suas ações.

A análise dos trechos selecionados para compor este artigo privilegia aspectos relacionados às dimensões do trabalho, tais como compreendidas pela Clínica da Atividade, e indícios de ressignificação de representações, tais como evidenciados na produção linguageira da professora. Desse modo, ainda que originalmente os dados gerados durante a laS com Taylor tenham sido analisados conforme os procedimentos previstos pelo ISD e sistematizados por Bronckart (2008), a seguir é promovida uma releitura desses trechos, a fim de explicitar a relação do procedimento de laS com o desenvolvimento docente.

\section{Conflitos no agir de uma professora iniciante}

A seguir são apresentados alguns trechos gerados a partir do procedimento de laS com a professora Taylor, tanto nos momentos de interação face a face quanto no comentário escrito elaborado posteriormente, a partir da transcrição dessa conversa inicial. A seleção desses trechos perfaz um caminho analítico que busca demonstrar de que 
maneira a utilização do livro didático enquanto ferramenta de trabalho docente (FREUDENBERGER, 2015a), envolvida por conflitos, pode ser considerada como promotora de desenvolvimento.

O primeiro excerto aqui apresentado foi gerado durante a terceira sessão de laS com a professora, realizada nas primeiras semanas do seu segundo semestre letivo enquanto professora de Língua Espanhola. É pertinente a ressalva de que nas duas primeiras sessões, realizadas no semestre anterior, o livro didático não foi mencionado nenhuma vez durante a geração dos dados. Logo no início da sessão, a professora iniciante busca contextualizar as instruções que oferecerá à sósia, relatando os acontecimentos da aula anterior.

[...]

\section{Excerto $01-$ Segmento $3.3^{3}$ (trecho)}

T: eh então na aula passada a gente TENTOU ver um filme

[...]

T: só que aí como só b/ só cumpri:u ... uh só-fo-ram cinquenta minutos de aula ainda sobrou: um bocado / sobrou um tempinho ... e graças a Deus eu tinha preparado a aula e aí eu parti pra ess/ pra outro assunto que não não tinha nada a ver com o: / eu achei horrivel porque não tinha nada a ver com o filme ... mas foi o único jeito que tinha de né ... de continuar a aula

S: isso foi na q/ na: [quarta?

$\mathrm{T}$ : [na quarta ... e: aí eu continuei a aula com eles e uma coisa que eu tô $\mathrm{f} /$ fazendo esse s/ semestre que eu não fazia no: no outro e: também porque: ... alguns deles reclamavam muito porque eu não usava o livro na sala de aula

S: uhu

T: [...] então eu tô usando um pouco mais o livro ... esse semestre

$[\ldots]$

Neste trecho de interação entre Taylor e a sósia é possível perceber diferentes dimensões pessoais e profissionais implicadas na atividade dessa professora iniciante, dentre eles aspectos afetivos - quando a professora avalia como "horrível" a maneira como a aula se desenvolveu - e relacionais - quando ela atende a uma reivindicação dos alunos. Esses aspectos dizem respeito à dimensão da atividade realizada pela professora iniciante e parecem ser mobilizados para justificar determinadas decisões por ela tomadas, motivos que parecem explicar sua implicação na atividade linguageira, marcada pelo uso constante da primeira pessoa do singular, ao contrário do que sugerido pelo procedimento (CLOT

\footnotetext{
${ }^{3}$ As referências remetem à sessão e ao Segmento de Tratamento Temático do qual foram extraídos os trechos apresentados. Assim S1.2, por exemplo, refere-se ao Segmento de Tratamento Temático 2 da Sessão 1 de Instrução ao Sósia.
} 
2001a). Desse modo, a atividade realizada, ou a experiência vivida (FRIEDRICH; GOUDEAUX; STROUMZA, 2004) com o emprego do livro didático, atua como suporte para as instruções endereçadas à sósia e parecem estar em transição entre o "vivido puro" - que ainda causa desconforto à professora - e o "saber da experiência" - que permite vislumbrar a utilização dessa ferramenta em um contexto específico em contraposição a uma prática anterior.

À dimensão do trabalho realizado somam-se ponderações que parecem advir de prescrições a ela endereçadas, ainda que não de maneira sistematizada. Assim, é possível reconhecer uma voz social ${ }^{4}$, possivelmente advinda do contexto acadêmico, que remete à seleção e à organização de temáticas para o ensino de Língua Estrangeira - que prevê, possivelmente, que as temáticas trabalhadas em aula sejam relacionadas e perfaçam uma sequência - e ao gerenciamento do tempo de aula - que indica a necessidade de preencher com tarefas todo o tempo destinado à aula. Além disso, a fala de Taylor deixa entrever um discurso social relacionado à importância da utilização do livro didático nas aulas.

O conflito gerado pela utilização do livro didático em suas aulas é também mencionado durante o comentário escrito, quando Taylor volta a explicitar os motivos que a levaram a inclui-lo em suas aulas.

\section{Excerto 02 - Comentário escrito (trecho)}

[...] Eu não utilizava muito o Livro didático (LD), passei a utilizar porque os alunos sentiam falta e falavam: 'Quando a gente vai usar o livro?'; 'Quando que a gente deve trazer o livro?' E então, eu passei a utilizá-lo mais. Porém, é muito difícil adaptar as atividades do LD para as aulas porque falta um pouco de conexão entre as atividades propostas pelo mesmo. [...]

O texto produzido por Taylor a partir da sua análise da interação face a face permite perceber que ela está envolvida em uma atividade de (re)construção de suas representações a respeito do livro didático como ferramenta de ensino, da sua interação com os alunos e de sua própria avaliação do conteúdo do livro didático face às (auto)prescrições que parecem fundamentar seu trabalho. Esse conflito, e a negociação a respeito dele, ganha relevância

\footnotetext{
${ }^{4}$ A noção de voz social faz referência a um dos elementos que formam os pré-construídos humanos, conforme expõe Bronckart (2008), qual seja, os mundos representados ou mundos formais, concebidos a partir da teoria habermasiana que propõe a existência de três tipos de operações de generalização aplicadas aos conhecimentos. Essas operações dariam origem aos mundos objetivo, social e subjetivo.
} 
para a professora a partir da laS, permitindo sua explicitação e, talvez, o acesso à dimensão do real de sua atividade.

A busca por integrar o livro didático em suas aulas pode ser percebida no Excerto 03, quando Taylor prescreve à sósia, completando o movimento de deslocamento de sua ação, os procedimentos que devem ser realizados na aula do dia seguinte à realização da laS.

\section{Excerto $03-\mathrm{S} .3 .14$ (trecho)}

T: eh ... uhm: ... aí depois desse texto ((apontando para o livro didático)) ... volta pra aquela primeira discussão ... e aí você pergunta se eles imaginavam que seria assim um bairro: latino

[...]

T: primeiro ... eh pede pra eles lerem e aí: eles vão ... fazer essa: atividade ((do livro)) individualmente / isso ... não tem problema ... eh ... e aí depois você confere com eles se tá certo

[...]

A decisão tomada por Taylor, a partir dos comentários de seus alunos, de utilizar o livro didático com maior frequência em suas aulas não está livre de conflitos. Assim, ainda que a aula prefigurada esteja majoritariamente embasada nos conteúdos propostos por essa ferramenta, a professora parece permanecer constrangida - note-se sua afirmação de que "não tem problema" adotar uma sequência de tarefas assim como estabelecida no livro didático. Desse modo, a atividade realizada durante o semestre em curso contrapõe práticas adotadas pela professora no semestre anterior, o que pode indicar que ela está em busca de novas possibilidades de atuação. Entretanto, essa vivência parece ainda estar representada de maneira muito próxima a uma falha em sua competência profissional, não estando ainda estável.

A preponderância do conflito de Taylor com o livro didático parece ter origem no seu trabalho realizado, que entra em choque com sua atividade idealizada ou sua atividade (auto)prescrita. Isso pode ser vislumbrado no Excerto 04, quando a professora instrui a sósia sobre a realização do planejamento para a aula seguinte.

\section{Excerto $04-5.3 .19$ (trecho)}

T: e pra quarta-feira: aí: ainda não tem nada preparado ((rindo))

S: aí eu vou ter que preparar a aula da quarta então

$\mathrm{T}$ : isso

[...]

T: então eh: você dá uma olhada no livro se: tem alguma coisa interessante ... geralmente não tem ... ma:s você olha o livro e aí pode ... da:r alguma: dica assim de 
fazer alguma coisa ... pelo menos se: você não quiser utilizar o texto daqui: mas ... você procura em outros lugares depois em casa

$[\ldots]$

Ainda que o movimento de deslocamento de sua ação em direção à sósia seja realizado plenamente pela professora nesse segmento, não é possível afirmar que todas as ações nele representadas constituam um conhecimento estável e generalizável. O que parece constituir uma representação estabilizada para Taylor é o fato de o livro didático não apresentar "coisas interessantes". Essa representação, aparentemente individual, entra em conflito com as demandas dos alunos, assim como demonstrado nos excertos anteriores. Uma resolução encontrada pela professora é, então, utilizar essa ferramenta como fornecedora de "dicas sobre coisas a fazer". Pode-se perceber, assim, que uma nuance da atividade real da professora - caracterizada como aquilo que o livro didático não contempla - dá origem a um embate que, ainda que esteja envolvido em avaliações negativas, permite uma nova significação sobre essa ferramenta e sobre a própria ação da professora.

Esse estatuto do livro didático também é debatido pela professora no seu comentário escrito, conforme trecho reproduzido a seguir.

\section{Excerto 05 - Comentário escrito (trecho)}

[...] E, uma fala minha me chocou, porque eu falei que 'geralmente não tem coisas interessantes no livro'. Eu achei esta minha fala muito forte, deveria ter falado de outra forma. Na verdade, acho que o que eu queria falar era sobre a dificuldade de adaptar as atividades do LD à sala de aula, à minha metodologia, aos meus alunos, etc. [...] O livro apresenta muita gramática, e para mim isto é um problema. [...]

O choque causado pela representação de sua avaliação sobre essa ferramenta parece levar Taylor a perceber a inconsistência entre um esquema de ação que lhe é familiar e a organização oferecida pelo livro didático. Ao perceber essa perturbação, pode-se argumentar que a professora esteja diante de aspectos centrais de sua atividade real - sua metodologia e o contexto no qual atua - trazidos à tona pela laS.

A relação dessa professora iniciante com o livro didático permanece sendo tematizada nas demais sessões de laS. Na quarta sessão, realizada cerca de um mês depois da anterior, Taylor oferece instruções à sósia sobre como conduzir a aula, assim como exemplificado no excerto abaixo. 
$[\ldots]$

\section{Excerto 06 - S.4.10 (trecho)}

T: ((folheando o livro)) tá aqui ... aí: eh: ... aqui no livro tem uma: explicaçãozinha / você pede pra que eles abram no livro / não tem problema nenhum / eh: do: pretérito perfeito

S: ta:

$\mathrm{T}:[\ldots .$.$] e aí você explica isso com eles / se tiver algum verbo por exemplo que eles$ falaram ah: "yo lei" então você fala "ah como ficaria isso no verbo: com o pretérito perfeito"

S: uhu

T: pede pra que: eles vão transformando junto com você ... e aí no final você fala "tá vendo ... não precisa de tanta explicação" / que eles cobram muito explicação de verbo $[\ldots]$

A produção linguageira de Taylor a respeito da utilização do livro didático como fonte de tarefas e explicações indica que essa ferramenta passa a ser majoritariamente utilizada em suas aulas, uma vez que a maior parte da sequência de ensino a ser supostamente empregada pela sósia advém dele. Entretanto, o conflito que permeava a sessão de laS anterior ainda se faz presente, já que Taylor utiliza novamente a expressão "não tem problema nenhum" para avaliar sua própria relação com essa ferramenta.

No decorrer da interação da professora iniciante com a sósia, essa dimensão de sua atividade real adquire um novo contorno. Não é apenas um confronto entre o livro didático e seu trabalho idealizado ou prescrito, mas entre as representações dos alunos e suas próprias sobre o ensino de Língua Espanhola. Ao sugerir uma fala para a sósia, no final do excerto, pode-se inferir que o teor dessa interação de Taylor com seus alunos seja recorrente. Desse modo, são os impedimentos impostos pela sua atividade realizada, que é absolutamente relacional, que promovem oportunidades para a professora reconhecer as vozes que alimentam o debate sobre o processo de ensino-aprendizagem de língua estrangeira.

Assim como na sessão anterior de laS, o comentário produzido pela professora a partir da análise da interação face a face retoma uma questão significativa relativa à sua atividade real em contraposição com seu trabalho realizado. Isso pode ser exemplificado no Excerto 07, reproduzido a seguir.

\section{Excerto 07 - Comentário escrito (trecho)}

[...] Eu acho que eu não sei explicar gramática muito bem. A minha 'sorte' é que na perspectiva interacionista o ensino de gramática é indutiva [sic], assim eles aprendem 
com o uso e nem se dão conta. No entanto, os alunos cobram muita gramática nas aulas e eu não consigo fazer isso. É como se fosse contra os meus princípios. [...]

Ao fazer referência a princípios que guiam seu trabalho, especificamente quanto ao ensino da gramática, a professora explicita um conflito entre características individuais suas (e apresentadas como negativas), a abordagem seguida por ela, ou prescrita pelo contexto formador, a abordagem supostamente preconizada pelo livro didático e as expectativas dos seus alunos. A solução encontrada por Taylor para esse confronto parece ser a utilização da sequência de tarefas proposta pelo livro didático. No entanto, tal resolução pode ser ainda momentânea, pois a professora afirma que a maneira como ela percebe a aprendizagem de Língua Espanhola contradiz aquilo que é oferecido pelo livro e esperado pelos alunos.

A resolução pessoal que Taylor encontra para esse conflito gerado pela utilização do livro didático parece ser sistematizada no comentário escrito por ela como análise à quinta sessão de laS, conforme Excerto 08 a seguir.

\section{Excerto 08 - Comentário escrito (trecho)}

[...] Preparar aulas já é difícil por si só, imagina quando não se tem de onde tirar assunto. No meu caso, terminamos (os alunos e eu) o livro umas 3 semanas antes das aulas acabarem, e isso dificultou um pouco o preparo das aulas, não que eu siga o livro à risca, mas ele ajuda às vezes quando estamos em busca de temas para as aulas, ou para vermos os assuntos que ainda precisam ser abordados. [...]

Se nas sessões anteriores foi evidenciada uma perturbação no agir de Taylor a fim de acomodar o livro didático como ferramenta de trabalho, este comentário indica que a professora passou a conferir ao livro um papel importante no seu planejamento das aulas. Desse modo, ainda que seu emprego gere ressalvas, particularmente quando usado na interação com os alunos, uma vez que ele não é seguido "à risca", o livro revela-se como uma ferramenta que cumpre uma importante função na organização e no planejamento das aulas. A explicitação desse uso permite perceber que novas possibilidades de ação, promovidas tanto pela atividade real quanto pela realizada, estão sendo construídas por Taylor.

O acompanhamento do trabalho docente representado por Taylor em seu primeiro ano como professora permitiu perceber distintos conflitos e a busca por soluções para eles. As implicações desses resultados para a pesquisa a respeito do desenvolvimento docente, 
bem como para a possibilidade de utilização da laS nesse contexto são explicitadas na seção seguinte.

\section{Considerações Finais}

O acompanhamento de Taylor durante seu contato inicial com o trabalho docente no papel de professora permitiu o acesso a diferentes conflitos e oportunidades de desenvolvimento profissional. No presente texto foram reproduzidos e analisados alguns trechos de sua produção linguageira, em contexto de laS, que podem indicar esses processos quando relacionados à integração do livro didático em seu agir.

Desse modo, ao retomar os objetivos propostos para o presente trabalho, é possível perceber as relações estabelecidas por diferentes dimensões do trabalho docente na constituição do trabalho de Taylor e representadas na laS. A professora, ao tematizar o uso do livro didático em suas aulas, apresenta conflitos entre a atividade realizada, na qual são protagonistas seus alunos, e sua atividade real, permeada por impedimentos relacionados à abordagem de ensino proposta pelo livro didático e por (auto)prescrições relativas à perspectiva de ensino idealizada, principalmente no que tange à apresentação da estrutura da Língua Espanhola.

$\mathrm{Na}$ interface entre essas dimensões constitutivas, a atividade realizada (e tematizada durante a laS) é apresentada como um conjunto de fatos que justificam determinadas decisões da professora iniciante. Em alguns dos trechos aqui analisados essa dimensão está imbricada em processos de julgamento negativo, seja do livro didático, das expectativas dos alunos ou da própria professora e suas capacidades. Além disso, é a partir de experiências já vivenciadas na interação com os alunos que Taylor pode generalizar determinadas ações e direcioná-las, supostamente, à sósia. Desse modo, os resultados aqui expostos corroboram as pesquisas de Friedrich, Goudeaux e Stroumza (2005) a respeito do papel cumprido pela experiência vivida na condução de laS com professores iniciantes. Todavia, ainda que a representação da atividade realizada tenha sido preponderante nos dados aqui apresentados, tal como foi na pesquisa das referidas autoras, a relação de Taylor com a atividade real é também significativa, e permite à professora o acesso a novas possibilidades de ação. 
Com relação ao objetivo de discutir como tais dimensões podem configurar um processo de desenvolvimento profissional, há de se considerar indícios de ressignificação presentes na produção linguageira. Desse modo, tais indícios apontam para movimentos de interiorização de um debate interpretativo a respeito da atividade docente que geram conflitos e, por sua vez, direcionam para a busca por soluções, ainda que pessoais e transitórias. Fica evidente que a integração do livro didático no agir docente de Taylor indica um processo desenvolvimental já que: i. ele é permeado por diferentes vozes sociais; ii. ele é conflituoso para a professora e iii. ele leva a um novo esquema de ação, ainda que parcial e insatisfatório para a professora iniciante.

Assim, a condução das sessões de laS com Taylor permitiu o reconhecimento desse debate social e a análise das soluções encontradas. Os indícios de um processo de desenvolvimento foram sendo revelados à medida que as instruções se sobrepunham ou se contradiziam de uma sessão a outra. Além disso, muitas das representações, sobre o livro didático nesse caso específico, ficaram disponíveis e evidentes já para a própria professora durante a produção do comentário escrito.

\section{Bibliografia Citada}

BOTA, Cristian. La mediation langagiere: praxeologie et gnoseologie. Estudos Linguísticos, n. 3, 2009, p.119-133.

BRONCKART, Jean-Paul. Une introduction aux théories de l'action. Carnets des sciences de l'éducation. Genebra: Université de Genève, 2005. Disponível em: https://www.unige.ch/fapse/publications-ssed/files/7015/7070/8670/Bronckart-2010-AO.pdf. Acesso em 22 de abril de 2013.

O agir nos discursos: das concepções teóricas às concepções dos trabalhadores. Campinas: Mercado de Letras, 2008.

Qu'est-ce que le développement humain? Interrogations, impasses et perspectives de clarification. In: Friedrich, Janette; Hofstetter, Rita; Schneuwly, Bernard (eds.). Une science du développement est-elle possible? Controverses du début du XXe siècle. Rennes: Presses Universitaires, 2013. p.207-226.

BRONCKART, Jean-Paul; BULEA, Ecaterina. La dynamique de l'agir dans la dynamique langagière. In: Barbier, Jean-Marie; Durand, Marc. (orgs.). Sujets, activités, environnements: approches transverses. Paris: Presses Universitaires de France, 2006. p.105-134. 
BULEA, Ecaterina. Linguagem e efeitos desenvolvimentais da interpretação da atividade. Campinas: Mercado de Letras, 2010.

CLOT, Yves. Clinique du travail et action sur soi. In: Baudouin, Jean-Michel; Friedrich, Janette. (orgs.). Théories de l'action et éducation. Bruxelas: De Boeck, $2001 a$.

Méthodologie en clinique de l'activité: I'exemple du sosie. In: Delefosse, Marie Santiago; Rouan, Georges (dir.). Les méthodes qualitatives en psychologie. Paris: Dunod, $2001 b$.

A função psicológica do trabalho. 2ed. Petrópolis: Vozes, 2007[1999], 222p.

FREUDENBERGER, Francieli. O trabalho do professor iniciante de língua estrangeira e as ferramentas docentes: um caminho para compreender o desenvolvimento? 2015. $542 \mathrm{fl}$. Tese - Linguística, Universidade Federal da Paraíba, João Pessoa, 2015 a.

Desenvolvimento e Figuras de Ação no quadro do ISD : reflexões a partir da teoria vygotskiana. In: Pereira, Regina; Medrado, Betânia; Reichmann, Carla (orgs.). Letramentos e Práticas Formativas: pesquisas tecidas nas entrelinhas do ISD. João Pessoa : Editora da UFPB, 2015b.

FRIEDRICH, Janette; GOUDEAUX, Annie; STROUMZA, Kim. Savoir d'action, expérience et language. Analyse d'um entretien d'instruction au sosie avec um étudiant em formation initiale d'enseignants. In: Anais do $5^{\circ}$ Colóquio Internacional Former des enseignantsprofissionnels: savoirs et compétences. Nantes, 2005.

GOUDEAUX, Annie; STROUMZA, Kim. De I'usage de l'instruction au sosie en formation initiale : les normes comme tiers dans le dialogue entre le sosie et l'instructeur. In: Anais do $39^{\circ}$ Congresso Ergonomie et normalisation. Genebra, 2004.

MACHADO, Anna Rachel. (org.). O ensino como trabalho: uma abordagem discursiva. Londrina: Eduel, 2004.

MILLER, Ronald. Vygotsky in perspective. New York: Cambridge University Press, 2011.

ODDONE, Ivar; RE, Alessandra; BRIANTE, Gianni. Redécouvrir l'expérience ouvrière: vers une autre psychologie du travail? Paris: Editions Sociales, 1981.

SAUJAT, Frédéric. Quand un professeur des écoles débutant instruit son "sosie" de son expérience. Les dossiers des sciences de l'éducation, n.7, 2002, p.107-117.

Fonction et usages de l'instruction au sosie en formation initiale. 2005. Disponível em: http://probo.free.fr/textes amis/instruction au sosie $f$ saujat.pdf. Acesso em 07 de dezembro de 2009.

SAUSSURE, Ferdinand de. Escritos de linguística geral. São Paulo: Cultrix, 2004. 
Curso de linguística geral. São Paulo: Cultrix, [1916] 2006[1916].

SCHNEUWLY, Bernard. Contradiction and development: Vygotsky and Paedology. European Journal of Psychology of Education, v.9, n.4, 1994, p. 281-291.

Le développement du concept de développement chez Vygotski. In: Clot, Yves (org.). Avec Vygotski. 2.ed. Paris: La Dispute, 2009.

Vygotski, l'école et l'écriture. Cahiers de la section des sciences de l'education, Genebra, n.118, out. 2008.

VYGOTSKY, Lev Sémionovitch. Le problème de l'enseignement et du développement mental à l'âge scolaire. In: SCHNEUWLY, Bernard; BRONCKART, Jean-Paul. (dir.). Vygotsky aujourd'hui. Neuchâtel: Delachaux et Niestlé, 1985 [1934].

A construção do pensamento e da linguagem. Tradução Paulo Bezerra. 2.ed. São Paulo: Martins Fontes, 2009 [1934].

' Professora do Departamento de Letras Estrangeiras Modernas (DLEM) da Universidade Federal da Paraíba (UFPB). Doutora em Linguística pela UFPB.

E-mail: francieli.freuden@gmail.com 